\title{
Bajo el signo del reconocimiento. Sobre la misión del pensar logotectónico ${ }^{1}$
}

\author{
In sign of the acknowledgment. \\ About the mission of logotectonic thinking
}

\author{
Martín ZuBIRIA \\ Universidad Nacional de Cuyo
}

Recibido: $18 / 10 / 2010$

Aceptado: 25/01/2011

\section{Resumen}

La aparición, en 1980, de la "Topologie der Metaphysik" de Heribert Boeder representó una transformación inimaginable del modo habitual de comprender la naturaleza del saber filosófico y, sobre todo, una transformación, fructífera como ninguna otra, de dos tesis fundamentales del pensamiento moderno: la referida a la comprensión de la $\dot{\alpha} \lambda \hat{\eta} \theta \varepsilon \iota \alpha$ como "desocultamiento" y la que hace del "ser del ente" la cosa unitaria del saber metafísico.

Treinta años después de la aparición de la obra susodicha, nos hemos preguntado, teniendo en cuenta los escritos publicados desde entonces por su autor, por la

\footnotetext{
1 Versión española, revisada y algo ampliada, de una conferencia redactada originalmente en alemán y pronunciada ante un pequeño auditorio, de manera privada, en el palacio de Bruche, Melle (Alemania), el 14 de marzo de 2009. Esta versión, por su parte, nació para ser expuesta en Buenos Aires, en el seno de la Academia Argentina de Ciencias, el 6 de mayo de 2010. Las palabras que siguen, siendo, como son, el fruto de un trato personal e ininterrumpido de muchos años con la Logotectónica, lejos de pretender "forzar al lector a que comprenda", para decirlo con el subtitulo de un famoso tratado de Fichte, sólo querrían alertar, a quien temiese navegar sin rumbo fijo por el mar de la filosofía, acerca de una novísima e insospechada posibilidad de orientarse en él con la debida firmeza. Que un pensamiento ha de defenderse por sí mismo y que sólo por sí mismo ha de acreditarse como verdadero, esto es algo que está fuera de discusión. Y no se nos escapa que, siendo sólo suya la fuerza de persuasión (PEIQW) que le es propia, toda recomendación exterior siempre será acogida con las debidas reservas.
} 
"misión" de su propio pensamiento. Uno que, desplegándose hasta volverse un todo, vino no sólo a iluminar las consumaciones de la filosofía en la realización de su tarea lógica, sino a edificar las tres esferas del presente de la razón: Historia, Mundo y Lenguaje.

Palabras clave: Metafísica, Logotectónica, Modernidad, Posmodernidad, Sabiduría.

\begin{abstract}
The 1980 appearance of "Topologie der Metaphysik", by Heribert Boeder, meant an absolute transformation in the ordinary way of conceiving the nature of philosophical knowledge. It meant above all a deep and fruitful transformation in two fundamental thesis of Modern Thought: that referred to the comprehension of the $\alpha \lambda \eta \dot{\eta} \theta \varepsilon \alpha$ as "desheltering", and that which makes the "being of beings" the unitary thing of the metaphysical learning.

Thirty years after the apparition of the mentioned work, we have asked ourselves, considering the writings published by the author since then, about the mission of his own thought. A thought that, developing up to a whole, came not only to illuminate the accomplishments of philosophy in the pursuit of its logical task, but to build the three Spheres of Reason's Present: History, World and Speech.
\end{abstract}

Keywords: Metaphysics, Logotektonik, Modernity, Posmodernity, Wisdom.

Aun a riesgo de que el exordio resulte algo pedestre, será bueno hacerlo con una aclaración terminológica, porque la expresión "pensar logotectónico" sigue siendo algo muy novedoso todavía y no puede dejar de causar extrañeza cuando se la oye por primera vez. Se trata, en efecto, de un nombre excogitado desde hace algo más de una década por el pensador alemán Heriberto Boeder, para denominar un cierto orden en la manera de proceder de la reflexión filosófica. Y así como este autor habla de un "pensar logotectónico" ["logotektonisches Denken"] - tal es el título de un artículo suyo publicado en Buenos Aires, en alemán, por la revista "Sapientia" (1998, 15-24)-, así también se sirve del término de "Logotectónica" ["Logotektonik"] para designar de manera unitaria tanto la actividad característica de ese pensar, como el fruto que le es propio: una obra cuya naturaleza constructiva o, mejor, "edificatoria" - de allí lo de "tectónico" -, se acredita en la formación de "silogismos" que, entendidos como relaciones triádicas de términos (rationes terminorum, $\lambda$ ó $\gamma \mathrm{o}$ ), antes que de proposiciones, se vinculan, a su vez, entre sí para 
hacer surgir figuras "lógicas" unitarias donde se espeja y condensa lo sustancial de cuanto ha sido hecho, y no simplemente "dicho", por la filosofía. "Logotectónico" es el pensar capaz de responder la pregunta de "¿Qué es esto - la filosofía?" de un modo tan eficaz como inesperado, conviene a saber, mostrándola como una serie ordenada de "figuras racionales", finita según la cantidad e infinita según la cualidad. Pero antes de avanzar en la comprensión de un pensar semejante, de su obra y, en particular, de su misión, conviene reparar por un momento en lo siguiente.

Si bien se mira, el hecho de que una doctrina filosófica sea identificada con un terminus technicus poco más o menos abstracto, está lejos de ser algo frecuente. Por lo general se habla de "la filosofía de Aristóteles" o de "la de Plotino", o de "la de Leibniz". Y aunque a veces tal o cual doctrina reciba un título que destaca su carácter propio, sea en el sentido de la forma o del contenido, con nombres tales como los de "dialéctica", o "doctrina de la ciencia", o "fenomenología", en las posiciones de Platón de Fichte y de Husserl, por ejemplo, ellos no dejan de ser, dentro de una historia singularmente larga, diferenciada y compleja, casos de excepción. No menos que el que nos ofrece la meditación heideggeriana, con aquel marbete, harto elocuente, de "pensar esencial" ["wesentliches Denken"] al que apeló, bien que en vano, para no ser confundida con la filosofía. Lo cierto es que tales títulos o denominaciones, y lo mismo vale para el de "pensar logotectónico", resultan útiles, aun sin ser imprescindibles, en la medida en que, tratándose de la obra de la razón, contribuyen a apartar de ella la sombra engañosa de lo meramente personal.

Al considerar en esta ocasión en una posición filosófica recibida en ambos hemisferios, por los muy pocos que hoy por hoy la conocen, con el gozo de una "buena nueva", nos proponemos comprender la naturaleza de su "misión", sin venir a repetir lo que ella bien sabe decir por sí misma - en este sentido podemos remitir a una serie de textos del propio Boeder aparecidos ya en nuestra lengua ${ }^{2}-\mathrm{y}$ sin descender a la vasta tierra de nadie de las opiniones. Tanto menos cuanto que el pensar logotectónico, como si de la misma intelección parmenídea se tratase, permanece "atado", según veremos, por unos lazos tan firmes como los de $\Delta$ ík $\eta$. Su obra pertenece así, por derecho propio, al orden de las consideraciones filosóficas generales y en ella acredita su validez la sentencia de Schiller según la cual "lo que se alcanza en el reino de la verdad, ha sido alcanzado para todos". ${ }^{3}$ Tal es la razón por la que el pensar logotectónico determina nuestra propia actividad académica con la fuerza ineludible de un destino.

\footnotetext{
2 Boeder, H.: El límite de la Modernidad y el legado de Heidegger, trad. y notas M. Z., Buenos Aires, Quadrata, 2003; del mismo autor, El final de juego de Derrida, trad. y notas M. Z., Buenos Aires, Quadrata, 2004; Topología de la Metafisica: la Época Media, trad., notas y epílogo M. Z., Navarra, Eunsa, 2009.

3 Véase su conferencia titulada “¿Qué significa y con qué fin se estudia la Historia Universal?”, con la que dio comienzo a su actividad como profesor en la Universidad de Jena.
} 
Pero, puesto que, a diferencia de Minerva, nacida ya adulta y armada incluso para la guerra de la cabeza de Zeus, ese pensar descansa sobre un trabajo ciclópeo sostenido durante largas décadas en medio del mayor silencio, no será inoportuna una breve orientación histórica acerca de su punto de partida.

Éste se sitúa en una investigación, de unas consecuencias tan graves como insospechadas, acerca del uso arcaico de las palabras griegas $\lambda$ ó $\gamma о \varsigma$ y $\alpha \lambda \eta \dot{\theta} \theta \varepsilon \alpha{ }^{4}{ }^{4}$ El estudio, ceñido al corpus de la literatura griega arcaica, con exclusión de las fuentes filosóficas, volvió manifiesto, con el rigor propio del saber filológico, el límite y, con él, la "modernidad" de la interpretación heideggeriana del sentido de ambas palabras. En efecto, así como $\lambda o ́ \gamma o \varsigma$, y ya la misma raíz $\lambda \varepsilon \gamma-$, no sólo significan "reunión" y "recolección", sino a la vez "discernir" y "hacer saber", así tampoco $\dot{\alpha} \lambda \eta ́ \theta \varepsilon \iota \alpha$ es jamás el simple fenómeno de la "desocultación" de una cosa cualquiera, sino, de manera precisa, el predicado de lo dicho o revelado, por quien sabe "cómo es", a quien es capaz de comprenderlo. "El $\lambda \hat{\eta} \theta \varepsilon \iota v$ de la $\alpha \lambda \eta \dot{\theta} \theta \varepsilon \iota \alpha$ es un encubrir que concierne a la razón."5 Por eso en la lengua griega se emplea el sus-

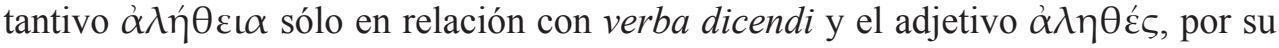
parte, según la totalidad de los testimonios literarios conservados, no aparece nunca predicado de una cosa, esto es, de algo privado de conciencia.

Pronto este resultado superó los límites de lo que habría podido parecer una simple rectificación de carácter filológico y obligó a realizar un ajuste de cuentas con la comprensión heideggeriana de la historia de la Metafísica; en particular con la tesis durísima, según la cual esa historia, pensada de manera unitaria como la de un preguntar incesante por el "ser del ente", se configura como "la época del olvido del Ser". Formulada en consonancia con el espíritu general de los "tiempos modernos" y deudora de la identificación escolar, prekantiana, de la Metafísica con la Ontología, esta tesis fue acogida, ya desde la aparición de Ser y Tiempo, como una suerte de revelación que venía a expresar, en términos poco menos que definitivos, el factum por antonomasia de la filosofía occidental. Lo cierto es que si aquello de "la ocultación del Ser" y del destino o "envío" (Geschick) de la misma, parece haber perdido no poco de la fuerza de persuasión que tuvo otrora, eso de que la filosofía ha preguntado siempre "por el ser del ente" ha seguido repitiéndose desde entonces, con la facilidad de un lugar común, al abrigo de toda polémica.

Y sin embargo la tesis de marras, puesta en el banco de pruebas, resultó ser menos concluyente que lo que aparentaba. El descubrimiento, realizado por BOEDER a comienzos de la década del 70 en un estudio titulado "¿Por qué motivo "ser del ente"'?, 6 de que la pregunta "por el ser del ente" es en rigor ajena tanto a la intelec-

\footnotetext{
4 Boeder, H.: "Der frühgriechische Wortgebrauch von Logos und Aletheia", ahora en Boeder, H.: Das Bauzeug der Geschichte, ed. G. Meier, Würzburg, Königshausen \& Neumann, 1994, pp. 1-30.

5 Boeder, H., op. cit., pág. 50.

6 Versión española en: Boeder, H.: El límite de la Modernidad y el legado de Heidegger, ed. cit., pp. $13-47$
} 
ción parmenídea como a la ciencia aristotélica y, de manera implícita, a de la reflexión platónica, no pudo sino conmover hasta en sus mismos fundamentos la meditación heideggeriana y mostrarla, por primera vez, bajo una luz enteramente nueva, sin que la opinión pública imperante en los círculos académicos se haya percatado, hasta el día que corre, de tamaño suceso. Y aquí lo que más ha importado, para un pensador de la tesitura intelectual y moral de Boeder, ha sido siempre, desde un comienzo, no el lado negativo del hallazgo, no el poder detenerse sobre la violencia histórica ejercida por la tesis heideggeriana ni la ocasión para batir el parche sobre algo que nuestro autor jamás tuvo la vanidad de considerar un "error", sino lo positivo a que ello hacía lugar: reconocer en su verdad, en la unidad de su despliegue metódico e incluso en su belleza "lógica", la obra consumada por la filo-sofía griega y, más aún, por la Metafísica toda a lo largo de su propia historia. Tal reconocimiento representaba una novedad inimaginable ante la exigencia heideggeriana de salir al encuentro de la Metafísica con el propósito de "vencerla" [überwinden] o, en su defecto, de dejarla librada a sí misma.

No cuesta trabajo admitir, siquiera de manera provisional, que todo saber se determina en orden al objeto que considera como su cosa propia. Si uno llegase a comprender, a pesar del aserto heideggeriano, que ese objeto ni es "el ser del ente" ni ha sido tampoco uno y el mismo a lo largo de la historia de la filosofía; ¿no habría de transformarse, y de un modo decisivo, nuestra comprensión de lo que la filosofía misma es? Llevar a cabo esa transformación por obra de una serie de pensamientos que fueron presentándose "con suavidad de paloma" en un mundo agitado sin cesar por las manifestaciones críticas de la mentalidad posmoderna, ha sido la misión propiamente dicha del pensar logotectónico. Una misión cumplida, como veremos, bajo el signo del "reconocimiento".

Ya en 1611, en su precioso Tesoro de la lengua castellana o española, ${ }^{7}$ Covarrubias consignaba, entre las acepciones del verbo "reconocer", la de "enterarse de alguna cosa de que no hay mucha claridad o noticia" y también esta otra: "confesar lo que uno debe a otro de beneficio y éste llamamos reconocido y reconocimiento". Porque en nuestra lengua, como en el resto de las románicas y también en las germánicas, y lo mismo en la latina y la griega, "reconocer" y "reconocimiento" no se limitan a designar el acto por el que algo ya conocido es identificado como tal a posteriori; también "reconocemos" al anoticiarnos de algo que ignorábamos, o bien al aceptar o aprobar una cierta relación. Pero cuando lo aprobado es un don o un bien recibido de manera gratuita, entonces "reconocer" vale tanto como "agradecer". Y es esta acepción la que aquí nos importa subrayar.

Ahora bien, para comprender en qué sentido el pensar logotectónico lleva a cabo su labor edificatoria "bajo el signo del reconocimiento", debemos detenernos

\footnotetext{
7 Ed. de Martín de Riquer, Barcelona, Editorial Alta Fulla, 2003.
} 
primero en un descubrimiento suyo, francamente notable. Se trata de algo en lo que, de puro manifiesto (propter nimiam facilitatem), nadie había reparado antes y que apartó de Boeder, también desde un comienzo, la fácil tentación de querer descubrir "errores" en lo que había sido pensado de manera "esencial". Nos referimos al hecho de que, en la Historia de la Metafísica, tal como la piensa Heidegger, en un doble sentido: a) en relación con un ser incondicionado, la esencia de la Técnica [das Gestell], y b) en la forma de un continuum que desemboca fatalmente en el peligro por antonomasia: la enajenación del hombre respecto de su esencia productiva, se reflejan, no por simples asociaciones eruditas, sino en virtud de una serie sorprendente de relaciones de orden sistemático, la Historia que se determina como una totalidad sometida, por un lado, a la "persona" del Capital (Marx) y, por otro, al imperio tiránico de la Moral (Nietzsche). En ambos casos, y otro tanto ocurre luego en la posición de Heidegger, la Historia es un continuum que obliga a pensar en el advenimiento de un tiempo venidero y, con él, en un nuevo comienzo para el habitar humano: sea en la forma universal o genérica de la "sociedad comunista", o en la particular de los futuros "amos de la tierra", o en la singular del "mortal" que, habiendo hecho suyo el pensar meditativo, habita en lo simple de la cercanía.

Siempre en un tiempo "por venir", llamado a no poder abandonar su condición de tal. De allí que en la posición de Heidegger, como en la de Marx y en la de Nietzsche, el pensamiento, empeñado en revelar el sentido de una Historia entendida como lo que "no debió ser", en orden a lo que vendrá - sea de manera necesaria (Marx), o posible (Nietzsche), o no imposible (Heidegger) -, se revele como el propio de una razón que, situada en un presente desgarrado entre el "ayer" que debemos superar y un "mañana" que no arriba, no se reconoce a sí misma como "filo-sófica"; en efecto, aquí se presenta una filosofía, dice Nietzsche en sus cuadernos póstumos, que "no quiere en absoluto ser llamada 'amor a la sabiduría' y que escribe en la puerta de su casa: $\mu \varepsilon ́ \mu \nu \eta \sigma$ ' à $\tau \iota \tau \tau \varepsilon \tilde{\imath} v$ " (cf. KStA, vol. 11, 487), "recuerda que debes recelar". Ante la imposibilidad de realizarse como la respuesta a una sabiduría, a una ooфía sensu stricto, la llamada "filosofía" de "la Modernidad en sentido singular" [Moderne] se condensa en una serie de representaciones de cuño apocalíptico - el mentado imperio universal de la sociedad comunista, el anillo del eterno retorno pregonado por Zaratustra, el cuadrante de tierra y cielo, divinos y mortales, la muerte como el escriño de la nada -, representaciones contra las que no podía dejar de levantarse el pensamiento posmoderno ${ }^{8}$, tachándolas de totalitarias y propugnando, como un acto de justicia, en nombre del pluralismo radical, anular la espera vana de un futuro no menos vano, hipotecado con la salvación de la esencia del hombre. Pero aun así, y a pesar de la inconsecuen-

8 Sobre la pertinencia de designar este pensamiento con el marbete de "submoderno" véase lo dicho más abajo a propósito del libro de Boeder, Die Installationen der Submoderne, citado en la bibliografía. 
cia que ello implica, la Posmodernidad se mantiene aferrada a la representación que hace de nuestra tradición filosófica la historia de la pregunta por el ser del ente y, en suma, la "historia de un error": sea el del "egocentrismo" moderno, o el del "logocentrismo" occidental, o bien, en última instancia, el del "endiosamiento" de la razón, "la más obstinada contrincante del pensar".

Pero, ¿es ello así realmente? Aun cuando una muchedumbre sin número, creyendo encarnar acaso un cierto espíritu de justicia vindicativa, pregone sin cesar tales asertos a lo largo de ambos hemisferios, el pensar logotectónico, entregado de manera imperturbable al cumplimiento de una misión que lo determina, la de hacerse cargo, bajo el signo del reconocimiento, del legado filosófico de nuestra tradición, nos enseña a verlo todo con otros ojos, con ojos nuevos.

¿Pero cuál es, en tal caso, aquella cosa, "de que no hay mucha claridad o noticia", como escribe Covarrubias, de la que debemos enterarnos? ¿Qué es aquello, si de "reconocimiento" hablamos, que nos "mueve a confesar lo que debemos de beneficio"? En primer lugar, el hecho de poder comprender que "la Modernidad en sentido singular" [Moderne] es un todo de posiciones del pensamiento vinculadas entre sí en torno a un núcleo formado por las meditaciones de Marx, de Nietzsche y de Heidegger, tal como lo muestra Boeder en "La articulación racional de la Modernidad" (Das Vernunftgefüge der Moderne, Friburgo, Alber, 1988). Pero no bien la Modernidad se descubre como una esfera de límites precisos, como un "mundo" articulado en una serie ordenada de posiciones o "lugares" ( pensar, la Metafísica, abandonada por fin a sí misma, acaba por mostrar su verdadera naturaleza histórica, que no es por cierto la de un continuum, sino la de un todo diferenciado en tres Épocas no subordinadas entre sí por relaciones de orden jerárquico. Ya desde hace largo tiempo y contra el imperio temible de la costumbre, el pensar logotectónico viene mostrando que nuestra tradición filosófica, al desplegarse históricamente, no tolera ser comprendida a la sola luz de su resultado hegeliano, como pretende Marx, ni a la sola comienzo parmenídeo, como afirma Heidegger, ni tampoco desde la de la pretendida mistificación paulina acerca del Crucificado, como sostiene Nietzsche. Siendo un todo perfecto, en sentido etimológico, puesto que acabado y completo, con su principio, su medio y su fin, la Metafísica, liberada del yugo de la interpretación moderna, presenta, en cada una de sus tres Épocas, no sólo una cosa, un pensar y una norma o destinación propios, sino, además, algo que resultará ser una verdadera piedra de escándalo para la comprensión escolar de la filosofía: nos referimos a una palabra "revelada", también ella de naturaleza epocal, que, por ser un saber acerca del destino del hombre merece por derecho propio el título de "sabiduría"; ese saber, esa "sofía", provoca, en virtud de su "lógica" inmanente o de la inteligibilidad que le es propia, una respuesta "filo-sófica" condigna. 
En la Topologie der Metaphysik (1980), todo esto se mostró por primera vez con la consistencia y la acumulación de pruebas que el caso requería. A lo largo de sus páginas se vio de pronto cómo aquella Metafísica comparada por Nietzsche con un "océano tenebroso", cobraba el carácter diáfano de un saber erigido no sobre un origen, ni sobre ninguna oscuridad mítica, sino sobre la claridad conceptual de un primer fundamento. Por otro lado, al haber reconocido cómo "la Modernidad en sentido singular" agotó sus tareas propias, la Logotectónica logró desprenderse de la superstición moderna que consiste en abjurar del saber, puesto que del logos, en favor del preguntar, del poner duda, del recelar; ello le permitió mostrar, en relación con cada posición filosófica, cómo la unidad inteligible de lo pensado en ella se despliega siempre en la forma de una secuencia de tres términos, presentes en la pregunta heideggeriana por "la destinación de la cosa del pensar". Pero si esta secuencia es presentada como un lógos (ratio) y al mismo tiempo como parte constitutiva de una figura de lógoi (rationes), es porque previamente ha podido ser "edificada" en cuanto tal, puesto que ella, siendo un todo, nunca podría ser algo simplemente dado en la inmediatez.

En esta labor edificatoria, el pensar logotectónico acredita lo que siempre ha sido para la filosofía el timbre de su pureza: mantenerse entregado a una relación de sí consigo, ajena a la pluralidad irreductible de los "puntos de vista" y al culto de la investigación entendida, con la naturalidad de lo obvio, como una "labor de equipo" destinada a no tener fin. Ya sólo por esto se comprende que la frecuentación de la Logotectónica permita realizar una experiencia harto infrecuente: tanto la de la belleza "matemática" de cuanto ha sido pensado por la filosofía, como la de la paz que anima el todo bien acordado de sus posiciones constitutivas; aquella paz definida por la mente agustiniana como "tranquillitas ordinis". [Salta a la vista que el reconocimiento de que aquí se trata se sitúa en las antípodas del interés "moderno" en nombre del cual un autor como Hartmann, por ejemplo, busca cegar las fuentes de los errores y equívocos enquistados secularmente en el pensamiento filosófico].

Es la experiencia de la tranquillitas ordinis despejada por el saber logotectónico lo que priva ya de asidero a la disposición de ánimo característica de "la Modernidad en sentido singular", característica de aquella conciencia suya de estar pisando una costra de hielo cada vez más frágil. Nietzsche veía en ello un desafío y a la hora de gritar "ia los barcos!" invocaba la virtud del hombre para quien la existencia siempre es guerra y su única paz la victoria. También la meditación heideggeriana, su "experiencia del pensar", se sabe irremisiblemente expuesta a la vecindad del peligro. Y para ella el reconocer, lejos de ser aceptación o aprobación $<$ Zustimmung>, es por el contrario "sólo el supuesto para toda confrontación" (Was heißt Denken? 31971, pág. 75). ${ }^{9}$ Ello es que esta disposición interior del pensar

\footnotetext{
9 Ortega y Gasset, por su parte (Espiritu de la letra, Madrid, Espasa, 1965), irá no menos lejos al ver en la ciencia "aquello sobre lo cual cabe siempre la discusión" (pág. 16; cursivas nuestras).
} 
moderno, que lo lleva a ver en el advenimiento de un nuevo comienzo la otra cara de un peligro de consecuencias fatales, pertenece a un presente - el de la mentada "Modernidad en sentido singular" - que, entre tanto, ha dejado de ser el nuestro y que sólo podría volverse tal en cuanto pensado de manera diferenciada. Porque ya no es el asecho del mal, ni la vecindad del peligro, ni la presencia "fatal" de "la esencia de la técnica" < Gestell $>$ lo que determina la tarea del pensar, sino, por un lado, la posibilidad inesperada de volver a oír, más acá de la Modernidad y de la Posmodernidad, la palabra sapiencial acerca de la distinción del hombre respecto de sí mismo y, por otro, la actividad del "edificar lógico" que abre aquella misma posibilidad.

¿Y en qué consiste este edificar? Se trata, por de pronto, de una labor de proporciones monumentales, que permite comprender a) cada una de las posiciones de nuestra tradición filosófica, más aún, b) cada una de las tres Épocas en que ella se articula, e incluso c) el todo de la Historia constituido por tales Épocas, mediante relaciones triádicas (rationes terminorum) que revelan, en cada caso, la misma transparencia "lógica" o conceptual. ¿Y qué se logra con una edificación semejante? Reconocer en nuestro presente histórico, al margen de intereses particulares, el lugar propio de la Sabiduría, el de una palabra que, en cuanto edificada con la consistencia de un "silogismo", se resiste a ser reducida a una simple "ficción poética".

En cuanto epocalmente diferenciada, esa Sabiduría es, primero, la de las Musas y tiene por portavoces a Homero, a Hesíodo y a Solón, luego, la del Espíritu Santo, revelada en los Evangelios Sinópticos, en las Epístolas Paulinas y en los escritos Joánicos, y por último la de la Humanidad del Hombre, poetizada por Rousseau, por Schiller y por Hölderlin. Pero si la Logotectónica, tal como se comprende a sí misma, es un pensar "al servicio de la Sabiduría", esta determinación corresponde a su contenido y nada dice acerca de la forma sui generis de su "diaconía". Ésta consiste en la pureza de un discernir progresivo, destinado a transparentar aquellos pensamientos que han introducido una diferencia fundamental en la totalidad de lo pensado filosóficamente.

La misión de la Logotectónica consiste así en salvar, a quien le presta oídos, contra el poder formidable de la Posmodernidad, cuyas pretensiones saben imponerse por doquier de manera totalitaria; en efecto, de no mediar la obra de la Logotectónica, ¿cabría no plegarse a los dictados del pensamiento anárquico (Merleau-Ponty, Foucault, Derrida), o del estructural (Jakobson, Barthes, LévyStrauss), o del analítico del lenguaje (Ryle, Austin, Dummett)? ¿En virtud de qué decisiones? ¿Acaso de las que pretenden reducir esa reflexión a lo efímero de una moda intelectual o al fruto de una ignorancia de la que habría de preservarnos alguna doctrina filosófica anterior, tenida por (la única) verdadera? En este sentido, el pensar logotectónico nos dispensa de los empeños siempre reiterados por remozar alguna filosofía de otrora, como si la misión histórica de la filosofía consistiese en la restauración de tal o cual verdad. De allí que la indiferencia ante la 
Logotectónica, aun a riesgo de que esto sea tomado por una simple hipérbole, pueda ser considerada hoy por hoy, in philosophicis al menos, como el verdadero pecado contra el espíritu, en la medida en que invalida, como un trampantojo de la arbitrariedad, todo instalarse, de manera unilateral, en alguna de las posiciones filosóficas habidas hasta el presente. Pues la Logotectónica ve la verdad de la filosofía no en una doctrina determinada, sino en la realización plena de una obra común que reclama, sin menoscabo de sus diferencias, ser pensada como un todo.

Es también por ello que la Logotectónica deshace la ficción moderna acerca de las pretendidas "preguntas eternas" de la Filosofía. En la medida en que el preguntar moderno satisfizo su destinación y cumplió por ende su cometido histórico, la Logotectónica quedó en franquía para poder reconocer la serie íntegra no ya de las preguntas, sino de las respuestas dadas por la razón a una sofíA erigida epocalmente en fundamento de la filo-sofía respectiva. En cuanto obra de la inteligencia, la Logotectónica comprende, para decirlo con Kant, sólo "aquello que ella misma produce según su propio esbozo" (C. r. p., pref. 2da. ed., pág. XIII).

Y como lo produce sólo a partir de cuanto posee verdadera sustancia, ya se trate de nuestra tradición filosófica, o del mundo de la Modernidad, o de la esfera de la Posmodernidad, uno jamás podría agradecer de manera suficiente, en un tiempo donde se afirma, sea con una buena cuota de cinismo, o sin ella, que "todo vale" (anything goes), la consecuencia con que la Logotectónica mantiene la concentración impertérrita de su mirada sobre las diferencias fundamentales que permiten articular un todo. Ya por eso logra contener con firmeza esa dispersión del pensa-

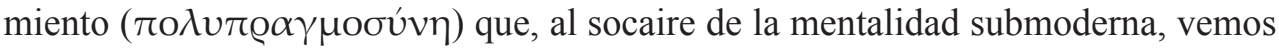
crecer en torno lo mismo que un desierto.

Y por mucho que la concentración, la pureza, la claridad de los conceptos hayan sido siempre un bien muy escaso, no es imposible pensar que, dadas ciertas circunstancias favorables, quien supiese cultivarlas habría de volverse un "mimado" por ellas, como dice Nietzsche. Y en tal caso no podría ya tolerar "el trato con los semiclaros, nebulosos, apetecedores, barruntadores... con su eterno revolotear y pretender asir, sin poder volar ni atrapar nada" ("Opiniones y sentencias varias”, § 2). No otra es la situación en que nos coloca la frecuentación de la Logotectónica, gracias a la cual uno se vuelve una suerte de ser mimado, precisamente en el sentido mencionado; nosotros, al menos, la hacemos enteramente responsable del hecho de no poder soportar ya ni el menor roce de buena parte de la llamada literatura secundaria en materia filosófica. ¿Y no es acaso infinito el beneficio que comporta el saber-

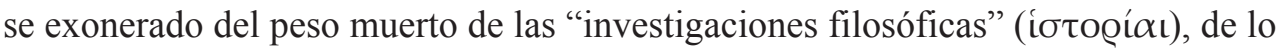
que ellas significan, o no significan, en la medida en que se han vuelto una labor de pane lucrando?

¿Traspasamos, acaso, el límite de lo razonable al decir estas cosas? Repárese por un momento en el modo habitual en que sale a nuestro encuentro la filosofía 
académica: es claro que ésta marcha siempre de la mano de los investigadores, quienes, en cuanto ejercen el oficio de tales, cultivan un campo determinado del saber filosófico, sea la Lógica o el Análisis del Lenguaje, la Filosofía Medieval o la Estética. La disciplina correspondiente es considerada en cada caso como algo dado, como un simple positum, hacia el que se vuelve el interés a partir de la convicción trivial de la conciencia cotidiana, según la cual es absurdo pretender "saberlo todo". En nombre de esa convicción se cultiva entonces la filosofía, al modo en que lo hacen los "hombres de ciencia", cada cual dentro de una cierta "área de interés". Pero esto, que parece tan razonable, supone, en el caso de la filosofía, hacer abstracción de su condición propia como saber, ignorar su forma, la de un todo determinado por un primer principio, e ignorar, en consecuencia, la infinitud de su saber. Infinitud que, más acá de la Modernidad y de la Posmodernidad, la Logotectónica nos pone ante los ojos.

Porque su doctrina, lejos de representar un nuevo "punto de vista" o una nueva "hipótesis" filosófica, confirma algo ya sabido en relación con el principio de la filosofía en general: aquello de que él ha de abarcar en sí los principios particulares, al vincularlos e incluirlos todos en sí mismo (Hegel, Enz. § 14). Inclusión que, en el caso de la Logotectónica, no supone ninguna "asunción" <Aufhebung $>$, tanto menos si ésta se comprende desde la idea del devenir histórico como un proceso continuo. Lo de la "inclusión en sí mismo" ha de comprenderse en orden a la determinación del presente en cuanto diferenciado; un presente donde cada principio y, con él, cada posición filosófica, resulta "topológicamente" indispensable para la edificación del todo al que pertenece.

Por no ser un nuevo "punto de vista", la Logotectónica no reclama para sí un interés que nos aparte de la consideración del todo. Permanece, por así decir, por detrás de lo pensado, limitándose a despojarlo de su inmediatez en la medida en que lo edifica con pureza "filo-lógica"; porque sólo así, sólo al cobrar la forma de una "figura racional" o de una ratio, lo pensado por la filosofía puede satisfacer su destinación contemporánea. Y sólo esas mismas rationes forjadas por la Logotectónica permiten, como nunca antes, comprender y explicar las diferencias que median entre las posiciones filosóficas en orden a la absolución de tareas comunes.

Que la mentada edificación de las figuras racionales provoque perplejidad y extrañeza es harto comprensible; porque si tales figuras impiden que la labor filosófica se realice, por así decir, "a la intemperie" (Fichte), así también representan una barrera insuperable contra lo arbitrario del interés particular en el trato con la filosofía. Pero quien fuese capaz de decir con Sócrates, como aquella vez junto al Iliso, bajo la sombra del plátano, "ciertamente, Fedro, yo mismo soy un enamorado de esas divisiones y sinopsis, que me hacen capaz de hablar y de pensar. Y si estimo que otro tiene la capacidad natural de ver en unidad y en multiplicidad, voy 'en pos de sus huellas como si fuese un dios"” (Fedro 266 B), ¿podría permanecer indiferente ante las figuras racionales edificadas por la Logotectónica? 
Y si el verlas dispuestas en series siempre triádicas provocase la impresión de lo artificioso, no sólo la observación de Kant en la Crítica del Juicio acerca de la naturaleza triádica de lo racional, 10 sino el simple detenerse a contemplar por un momento la estructura de una obra como la Suma Teológica del Aquinate, por ejemplo, bastaría para hacernos reparar en lo nulo de aquella impresión. Pero acaso el remedio más seguro para no caer en la fácil tentación de considerar el edificio logotectónico como una "mera construcción" consista en advertir que "el mundo del pensamiento debe comenzar por ser edificado; ninguna unidad pura existe como algo dado a la mano [en la inmediatez]" (Hegel, Vorlesungen über die Geschichte der Philosophie, ed. Suhrkamp, vol. 18, 203). Jamás una masa de elementos se organiza por sí sola formando un todo; ello es algo que realiza sólo la inteligencia y supone una libertad que uno ha de hacer suya por sí mismo en cada caso.

Al reconocer lo digno ser pensado como la serie íntegra y epocalmente diferenciada de las posiciones filosóficas habidas hasta el presente, la Logotectónica impide aferrarse a una de ellas en desmedro de las restantes. No cabe así, por ejemplo, "absolutizar" una posición como la de Hegel; la Logotectónica muestra, en efecto, cómo la ciencia del concepto especulativo, aun siendo un "resultado", lleva a cabo, junto con el pensamiento de Fichte y el de Kant, la unidad de una obra común, conviene a saber, la concepción de la sofía propia de la Época Última. ${ }^{11}$

La misión del pensar logotectónico consiste pues en el reconocimiento de un presente diferenciado, integrado por tres totalidades: la Historia de lo que en nuestra tradición ha sido la filo-sofía en cuanto amor sapientiae, el Mundo de la Modernidad en sentido singular y el Lenguaje, diferenciado en sí mismo, de la reflexión posmoderna. Que la obra de la Posmodernidad descansa en la unidad "lógica" de sus tres dimensiones constitutivas - las ya mencionadas del pensamiento anárquico, estructuralista y analítico del lenguaje (pues éste no deja de ser un fenómeno inequívocamente posmoderno) - y que el saber atenerse sólo a las doctrinas que introducen una diferencia fundamental, permite edificar esa obra como un todo inteligible digno del debido reconocimiento, lo ha mostrado Boeder en un libro sólido como pocos, que aguarda todavía a sus lectores: Die Installationen der Submoderne. Zur Tektonik der heutigen Philosophie, aparecido en Wurzburgo en el año 2006.

¿Y qué ocurre con el reconocer, cuando lo reconocido no es sino el mismo pensar logotectónico? ¿Qué significa, en tal caso, reconocer, dejarse ganar por la fuerza de persuasión que lo anima? Por de pronto, poder resistir al prurito de llegar a ser uno mismo independiente, o "creador" incluso, en el campo del pensamiento, como si la única posibilidad de pensar algo "por sí mismo" consistiese en compor-

\footnotetext{
10 "Introducción", IX, nota 2.

11 Cf. Boeder, H.: "Die conceptuale Vernunft in der Letzten Epoche der Metaphysik", Abhandlungen der Braunschweigischen Wissenschaftlichen Gesellschaft 43, 1992, pp. 345-360.
} 
tarse frente a ello de manera "crítica"; como si Hegel se hubiese equivocado al tildar de "peste" el querer "pensar por cuenta propia" sin que medie para ello necesidad alguna de orden superior. Entregarse a semejante afán sin dejar de mirar de reojo, al hacerlo, en qué medida ello promueve la consideración tributada a la propia personita - das Persönchen, que decía Fichte - significa pasar de largo ante el pensar, ante su cosa propia, puesto que, por sobre todo, ante su destinación. Porque la única voluntad llamada a rendir fruto en la filosofía es la que, permaneciendo atenta a la distinción del hombre respecto de sí mismo, vive en el reconocimiento del presente de cuanto ha sido pensado por la filosofía misma. Reconocimiento que depende no sólo de la enjundia de lo pensado, sino, al mismo tiempo, del propósito racional de considerarlo con la pureza que le es propia.

Cuando ello ocurre, la filosofía vuelve a convertirse en lo que ha sido desde siempre para la conciencia cotidiana: una piedra de escándalo. Ante ella se diferencian los hombres y sus caminos respectivos, de manera inevitable, cuando se trata del pensar. ¡Cómo podría ser otro su destino si, como dice Platón en el Gorgias, "cada cual se alegra cuando se le habla con arreglo a su pensamiento y de lo contrario se irrita" (513 b)! Pero si toda filosofía es la de su tiempo, y si tanto para el juicio moderno como para el posmoderno cualquiera de las formas históricas de la filosofía representa una comprensión menoscabada de la verdad, ¿cómo podría entonces el pensar filosófico ser ninguna piedra de escándalo? Esta antigua "dignidad" suya sólo la recupera por obra de la Logotectónica, porque ésta en ningún caso se deja reducir a una suerte de "historia de la filosofía". Considerarla de este modo es el expediente más sencillo para evitar el encuentro con un pensamiento que, como ningún otro en los días que corren, nos mueve a preguntar, remedando a Calicles, en el citado diálogo platónico, si es que Boeder habla en serio o si bromea, porque si habla en serio y es realmente verdadero lo que dice...

Pero ¿cómo decidir acerca de la verdad de lo dicho, tratándose de un saber que no es meramente "natural"? Acaso, ante él, uno esté supeditado a un movimiento interior, conocido también por la razón apocalíptica de la Modernidad bajo el nombre de "salto" $<$ Sprung $>$, al que tradicionalmente se le aplicaba el epíteto de "providencial".

Ello explica la siempre inveterada soledad que rodea la "buena nueva" del pensar logotectónico, en la que bien cabría ver el signo de que uno marcha in philosophicis por el buen camino. Un signo que se ha de leer con el debido discernimiento, porque si hay casos, y así lo supo Zaratustra, en que la soledad se padece, también hay otros en que ella tiene el valor de una condición. La soledad del pensar logotectónico, en efecto, no se reduce a la experiencia humana, demasiado humana, de quien se topa por doquier con la conocida sordera "de los oídos, los ojos y la mente"; en su caso no cabe hablar de un cierto desinterés o desestimación por parte del público filosófico, porque el pensar logotectónico se vio llevado ya desde un 
comienzo, para poder llevar a cabo su tarea, por un camino parmenídeo, apartado de las opiniones de los mortales puesto que de la brega de la filosofía académica. Por lo demás, si uno repara ya en la indiferencia, ya en la hostilidad con que, en ocasiones, sobre todo cuando se actúa en un mismo campo de estudio, se comportan entre sí los grupos de investigadores, y cuando se ha hecho la experiencia, además, de lo difícil que resulta, incluso entre quienes cultivan profesionalmente la filosofía, poder permanecer a salvo del odium figulinum, aquel aborrecimiento del alfarero por el alfarero, conocido ya por Hesíodo, entonces el camino solitario de la Logotectónica se vuelve, a la vez, un amparo y una gracia.

En su escrito inédito, titulado "Logos versus lenguaje", Boeder asienta por contera un breve párrafo, digno de lectura y relectura, donde él se comprende a sí mismo no como un "filósofo" - con qué derecho podría hacerlo, tras la renuncia expresa a la filosofía por parte de la Modernidad en sentido singular; con qué derecho, después de aquel final de la "Carta sobre el humanismo" -, sino como un "filólogo", en el sentido etimológico del término; sentido que no acepta, por cierto, la identificación trivial de "logos" con "palabra". El párrafo dice así: "El 'filólogo', a diferencia del filósofo, se ve llevado a leer las proporciones de lo pensado, edificándolas, para liberarlas así de su actual desfiguración y afeamiento. Un LOGOS quiere ser no sólo verdadero, sino, antes bien, bello, cautivador."

Esto obliga a señalar otro aspecto en la misión de la Logotectónica, porque en consonancia con lo dicho ella viene a salvar, mediante el pensar y para él, la belle$z a$ propia de la obra de la inteligencia filosófica; aquélla, tal como se manifiesta en la unidad arquitectónica de una cierta figura "lógica", orienta de manera decisiva el reconocimiento logotectónico de lo que fue otrora la filosofía, más acá de sus desfiguraciones y mutilaciones modernas y posmodernas, cuya razón de ser supera ciertamente el orden de las consideraciones epistemológicas.

¿Cómo responde a ello la Logotectónica? Como lo hacía Sócrates, mutatis mutandis, al afirmar que no tenía ninguna doctrina propia y positiva acerca de los temas tradicionales de la filosofía. Para cumplir con la misión que la determina, la Logotectónica comenzó por deslindar la meditación de la "Modernidad en sentido singular" respecto del todo de la historia que la precede, tras haber advertido que, en la repulsa moderna de esa historia y en la violencia que le es propia, una razón diferente de la filo-sófica edificaba su propio reino. Fue así como, al avanzar luego, bajo el signo del reconocimiento, hacia la comprensión del todo de la historia, el pensar logotectónico supo hacer justicia a la verdad, a la bondad (puesto que a la justicia) y a la belleza de lo pensado filosóficamente, desde Parménides hasta Hegel, pasando por Agustín. Se trataba de mostrar por doquier, con una transparencia cada vez mayor, "cómo es", según la norma que impide la confusión entre "cómo tiene que ser" y "cómo no tiene que ser". 
El todo de lo pensado acabó por articularse en la Historia del amor sapientiae, el Mundo de la Modernidad en sentido singular y el Lenguaje de las instalaciones del pensar submoderno; así edifica la Logotectónica el presente de la razón, confiriéndole la forma de una articulación racional unitaria y diferenciada a la vez. Ante lo cual, la inquietud moderna y submoderna, el desasosiego de habitar en un presente finito, limitado por el yerro del pasado y por un futuro retenido, se ve llevado a desaparecer.

Si ha llegado ya el tiempo en que debe cesar la difamación del logocentrismo de nuestra tradición y ceder el paso a su alabanza, por razones que la Logotectónica ha expuesto debidamente en su lugar, ${ }^{12}$ entonces no ha de ser ella menos alabada, pues en su condición de técnica 'filo-lógica', el objeto propio de su pensamiento ya no es ni los actos verbales que indaga el análisis del lenguaje, ni las formas variopintas del poder que rebelan al pensamiento anárquico, ni tampoco "el habitar en el lenguaje del poetizar y del pensar", sino la posibilidad de fundar en el presente un acceso a la palabra sapiencial que reclama del hombre su distinción respecto de sí mismo.

De este modo se ha producido ya en el horizonte del pensar contemporáneo un desplazamiento hacia una situación de una novedad sin parangón: en medio de un sosiego que todo lo transfigura, nos hallamos bajo una constelación desconocida hasta el presente. De pronto, cuando nada podía predecirlo, la inquietud pendular de una reflexión extrínseca volcada por igual hacia el futuro y hacia el pasado, sea para llegar a superar mediante el primero el presente de lo que no debe ser, sea para manipular el segundo con la violencia totalitaria de la conciencia cotidiana, ha cesado. Aristóteles supo que, por la condición extrínseca de su causa final, todo movi-

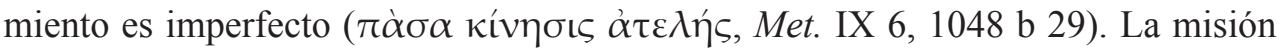
del pensar logotectónico consiste, en suma, en haber recuperado, más acá de los límites de la Modernidad y de la Posmodernidad, y sin excluir ambas esferas, la noción de lo perfecto, en el sentido de lo consumado (

$\mathrm{Si}$ ante la presencia de algo prodigioso, en el sentido de la inteligencia, la conciencia cotidiana se defiende con una afirmación que le cuesta poco para repetir: "no es posible", "no puede ser", la filo-logía, su edificar logotectónico, nos enseña a reconocer, por el contrario, cómo lo "real" es sólo lo maravilloso, sólo lo que mueve a exclamar, una y otra vez, con el giro homérico, $\theta \alpha \tilde{v} \mu \alpha$ i $\delta \varepsilon ́ \sigma \theta \alpha \iota !$

\section{Bibliografía}

Boeder, H.: Topologie der Metaphysik, Friburgo/Munich, Alber, 1980

BoEDER, H.: Das Vernunft-Gefüge der Moderne, Friburgo/Munich, Alber, 1988

12 Cf. supra nota 2. 
Boeder, H.: "Die conceptuale Vernunft in der Letzten Epoche der Metaphysik", Abhandlungen der Braunschweigischen Wissenschaftlichen Gesellschaft 43, 1992, pp. 345-360.

Boeder, H.: Das Bauzeug der Geschichte. Aufsätze und Vorträge zur griechischen und mittealterlichen Philosophie, Würzburg, Königshausen \& Neumann, 1994

Boeder, H.: Seditions. Heidegger and the Limit of Modernity. Translated, edited and with an Introduction by Marcus Brainard, New York, SUNY, 1997

Boeder, H.: "Logotektonisches Denken", Sapientia, 1998, pp. 15-24

Boeder, H.: El límite de la Modernidad y el legado de Heidegger (Selección de artículos), trad. y notas de M. Z., Buenos Aires, Quadrata, 2003

BoEDER, H.: El fin de juego de Derrida (Selección de artículos), trad. y notas de M. Z., Buenos Aires, Quadrata, 2004

Boeder, H.: Die Installationen der Submoderne. Zur Tektonik der heutigen Philosophie, Würzburg, Königshausen \& Neumann, 2006

Boeder, H.: Topología de la Metafísica: la Época Media, trad., notas y epílogo por M. Z., Navarra, Eunsa, 2009

Martín Zubiria

Universidad Nacional de Cuyo

CONICET

mzubiria@logos.uncu.edu.ar 